\title{
Nutrientes minerais em pimentão fertirrigado sob lâminas de irrigação e doses de potássio
}

\author{
Francimar S Albuquerque ${ }^{1}$; Ênio FF Silva ${ }^{1}$; Egídio Bezerra Neto ${ }^{1}$; Amanda ER Souza² ; Alexandre N \\ Santos ${ }^{1}$ \\ ${ }^{1}$ UFRPE, R. Dom Manoel de Medeiros s/n, Dois Irmãos, 52171-900 Recife-PE; franciufrpe@gmail.com; enio.silva@pq.cnpq.br; \\ egidiobn@yahoo.com.br; alexandrens14@yahoo.com.br; ${ }^{2}$ UFPE, Av. Prof. Moraes Rego 1235, Cidade Universitária, 50670-901 Recife- \\ PE; amandarocha228@gmail.com
}

\begin{abstract}
RESUMO
O presente trabalho teve como objetivo avaliar as concentrações de macronutrientes em folhas e frutos de plantas de pimentão submetidas a lâminas de irrigação e doses de potássio via fertirrigação. $\mathrm{O}$ delineamento experimental adotado foi inteiramente casualizado, em esquema fatorial $5 \times 2$, com quatro repetições, sendo cinco lâminas de irrigação $(80,90,100,110$ e $120 \%$ da ETc) e duas doses de potássio ( 80 e $120 \mathrm{~kg} \mathrm{ha}^{-1}$ de $\left.\mathrm{K}_{2} \mathrm{O}\right)$, aplicadas parceladamente de acordo com a fase fenológica. A fertirrigação foi feita por intermédio de um sistema de irrigação por gotejamento, com emissores autocompensantes, instalado em uma bateria de 40 lisímetros de drenagem cultivados com pimentão (híbrido Maximos F1), localizada no campus da Universidade Federal Rural de Pernambuco em Recife-PE, cuja parcela experimental era composta por três plantas em cada lisímetro. Os resultados mostraram as seguintes ordens de concentração de nutrientes: $\mathrm{N}>\mathrm{K}>\mathrm{Cl}>\mathrm{Mg}>\mathrm{Ca}>\mathrm{P}>\mathrm{S}>\mathrm{Na}$, nas folhas, e $\mathrm{K}>\mathrm{N}>\mathrm{Cl}>\mathrm{P}>\mathrm{Ca}>\mathrm{S}>\mathrm{Mg}>\mathrm{Na}$, nos frutos. As máximas concentrações de $\mathrm{K}$ e $\mathrm{Mg}$ nas folhas foram obtidas com as lâminas de irrigação de 103,43 e 105,54\% da evapotranspiração da cultura, respectivamente; as doses de $\mathrm{K}$ não inibiram a absorção dos nutrientes, exceto para $\mathrm{Mg}$ e $\mathrm{S}$ nas folhas.
\end{abstract}

Palavras-chave: Capsicum annuum, fertirrigação, lisímetros de drenagem, nutrição mineral.

\begin{abstract}
Mineral nutrients in fertigated sweet pepper under irrigation depths and potassium doses

The aim of this study was to evaluate the macronutrient concentrations in leaves and fruits of sweet pepper plants subjected to irrigation depths and potassium doses by fertigation. The experimental design was completely randomized in factorial scheme $5 \times 2$, with four replications, the factors being five water depths $(80$, $90,100,110$ and $120 \%$ of ETc) and two potassium doses (80 and $120 \mathrm{~kg} \mathrm{ha}^{-1}$ of $\mathrm{K}_{2} \mathrm{O}$ ) parceled according to phenological phase. The fertirrigation was made by a drip irrigation system, with selfcompensable emitters, installed in a battery of 40 drainage lysimeters cultivated with sweet pepper plants (Hybrid Maximos F1), located at the Federal Rural University of Pernambuco (UFRPE) in Recife, Pernambuco state, Brazil, whose experimental plot consisted of three plants in each lysimeter. The results showed the following order of nutrients content: $\mathrm{N}>\mathrm{K}>\mathrm{Cl}>\mathrm{Mg}>\mathrm{Ca}>\mathrm{P}>\mathrm{S}>\mathrm{Na}$, in the leaves, and $\mathrm{K}>\mathrm{N}>\mathrm{Cl}>\mathrm{P}>\mathrm{Ca}>\mathrm{S}>\mathrm{Mg}>\mathrm{Na}$, in the fruits. The highest concentrations of $\mathrm{K}$ and $\mathrm{Mg}$ in the leaves were obtained with the water depths of 103.43 and $105.54 \%$ of crop evapotranspiration, respectively; the K doses did not inhibit the absorption of nutrients, except for $\mathrm{Mg}$ and $\mathrm{S}$ in the leaves.
\end{abstract}

Keywords: Capsicum annuum, fertigation, drainage lysimeters, mineral nutrition.

(Recebido para publicação em 25 de junho de 2012; aceito em 5 de novembro de 2012) (Received on June 25, 2012; accepted on November 5, 2012)

$\mathrm{O}$ pimentão (Capsicum annuum) é cultivado em todo o território brasileiro, tratando-se de uma das dez hortaliças de maior importância econômica no mercado hortifrutigranjeiro nacional (Echer et al., 2002). É uma solanácea perene, tipicamente de origem americana, no entanto é cultivada como planta anual. A ordem decrescente de absorção dos macronutrientes por esta cultura é K, Ca, N, Mg, S e P (Filgueira, 2003).

Marcussi (2005) afirma que a eficiência de absorção de nutrientes pela planta está relacionada como uma das mais importantes vantagens da fertirrigação, técnica esta que oferece à planta 0 nutriente prontamente disponível na solução do solo para ser absorvido. Desta forma, há uma necessidade crescente de obter parâmetros de avaliação do estado nutricional da planta a fim de corrigir possíveis deficiências ou toxidez. O emprego da fertirrigação tem possibilitado a otimização do uso de insumos em diferentes culturas irrigadas, tanto em aspectos relacionados à produtividade quanto à qualidade dos produtos obtidos, sendo mais notável sua adoção em culturas irrigadas por sistemas de irrigação localizada (Oliveira \& Villas Bôas, 2008).

A quantidade dos nutrientes minerais nas partes das plantas tem uma impor- tância fundamental na identificação das necessidades das culturas, o que contribui de certa forma para a estimativa da adubação com base na exportação dos nutrientes minerais (Malavolta, 2006). O potássio é um macronutriente essencial que atua na ativação de varias enzimas, está envolvido na síntese das proteínas, atua no controle osmótico das células, confere resistência às secas e geadas, e também está envolvido nos mecanismos de defesa das plantas às pragas e doenças (Marschner, 1995).

O presente trabalho teve como objetivo avaliar as concentrações de macronutrientes em folhas e frutos de plantas de pimentão submetidas a lâ- 
minas de irrigação e doses de potássio via fertirrigação.

\section{MATERIAL E MÉTODOS}

O experimento foi conduzido na estação lisimétrica situada no Campus da Universidade Federal Rural de Pernambuco (UFRPE), em Recife-PE ( $8^{\circ} 01^{\prime} 05^{\prime} \mathrm{S}, 34^{\circ} 56^{\prime} 48^{\prime}$ 'O, altitude de $6,5 \mathrm{~m})$. O clima, de acordo com a classificação de Koppen, é As, megatérmico tropical (tropical úmido), com temperatura média do mês mais frio superior a $18^{\circ} \mathrm{C}$ com precipitações de outono e inverno, cujas médias anuais de umidade relativa do ar, de precipitação pluvial e temperatura são $76 \%, 1.500 \mathrm{~mm}$ e $26^{\circ} \mathrm{C}$, respectivamente (Albuquerque Filho et al., 2009).

A área experimental possui dimensão que totaliza 464,4 $\mathrm{m}^{2}$ de área plantada, possuindo uma bateria de 40 lisímetros de drenagem, preenchidos com solo de textura arenosa, classificado como Neossolo Quartzarênico (Embrapa, 2006). Cada lisímetro constituía-se de uma caixa de cimento reforçado com fio sintético - CRFS (linha Brasiflex-Brasilit), troncônicas, com capacidade de $1.000 \mathrm{~L}$, diâmetro na borda superior de $1.360 \mathrm{~mm}$ e altura de $745 \mathrm{~mm}$ (Albuquerque Filho et al., 2009).

O delineamento experimental adotado foi inteiramente casualizado, em esquema fatorial $5 \times 2$, com quatro repetições, sendo cinco lâminas de irrigação $(80,90,100,110$ e $120 \%$ da ETc) e duas doses de potássio (80 e $120 \mathrm{~kg} \mathrm{ha}^{-1}$ de $\mathrm{K}_{2} \mathrm{O}$ ), aplicadas de forma parcelada de acordo com a fase fenológica da cultura (Trani \& Carrijo, 2004).

As aplicações foram feitas por intermédio de um sistema de irrigação por gotejamento, com emissores autocompensantes, "online", modelo Katif, tipo botão, de fabricação Plastro, instalado nos lisímetros. A vazão do emissor especificada pelo fabricante é de 3,75 L $\mathrm{h}^{-1}$, sendo a aferida em campo 3,90 $\mathrm{L} \mathrm{h}^{-1}$.

Foi determinada a uniformidade da distribuição da água e a uniformidade de aplicação das doses de potássio, que depende da distribuição uniforme da água e da concentração do elemento no volume de solução coletado, em duas épocas de amostragem, utilizando o Coeficiente de Uniformidade de Christiansen (CUC) e o Coeficiente de Uniformidade de Distribuição (CUD), propostos por Bernardo et al. (2008). Para ambas as doses de potássio aplicadas (80 e $120 \mathrm{~kg} \mathrm{ha}^{-1}$ $\mathrm{K}_{2} \mathrm{O}$ ), o CUC e o CUD médios encontrados para a distribuição de água foi de 96,07 e 93,92\%, respectivamente. Para a uniformidade de aplicação das doses, as médias do CUC e CUD foram 86,37 e $81,18 \%$, respectivamente, para a dose $\mathrm{D}_{1}$; para a dose $\mathrm{D}_{2}$, foram encontrados 85,05 e $77,56 \%$ para o CUC e o CUD, respectivamente.

Os lisímetros foram cultivados com o pimentão Híbrido Maximos F1 (EliSem, Clause Vegetable Seeds), cuja parcela experimental era composta por três plantas em cada lisímetro, com espaçamento de $0,40 \mathrm{~m}$ entre plantas e 1,30 m entre linhas. As mudas de pimentão foram adquiridas em produtor registrado no Registro Nacional de Sementes e Mudas (RENASEM), localizado no Município de Bezerros-PE.

A fim de minimizar o efeito de advecção sobre as plantas dos tratamentos, mudas de pimentão do mesmo híbrido foram plantadas na área externa aos lisímetros, utilizando o mesmo espaçamento. A irrigação foi realizada diariamente, e as lâminas de irrigação foram calculadas a partir da ETc conforme equação:

$$
\mathrm{ETc}=\mathrm{ETo} \cdot \mathrm{Kc} \cdot \mathrm{Kl}_{\mathrm{m}}
$$

Onde $\mathrm{ETc}=$ evapotranspiração da cultura $\left(\mathrm{mm} \mathrm{d}^{-1}\right)$; ETo= evapotranspiração de referência de Penman-Monteith $\left(\mathrm{mm} \mathrm{d}^{-1}\right) ; \mathrm{Kc}=$ coeficiente de cultivo (adimensional); $\mathrm{K} 1 \mathrm{~m}=$ coeficiente de localização médio (adimensional).

$\mathrm{O} \mathrm{K} / \mathrm{m}$ foi estimado pela média de quatro valores de coeficiente de localização, segundo Pizarro (1996), que dependem do valor da fração de área sombreada pelo cultivo (S). O valor de $\mathrm{S}$ foi obtido segundo recomendação apresentada pelo mesmo autor. A ETo e a precipitação foram obtidas na estação meteorológica automatizada provida de sensores e armazenador de dados necessários para determinação da ETo de Penman-Monteith (Campbell
Scientific modelo CR1000/CFM100/ OS100), utilizadas no cálculo das lâminas de irrigação conforme os tratamentos.

No manejo da irrigação, os valores de Kc utilizados diariamente de acordo com a fase fenológica da cultura foram: 0,40 (da emergência até $10 \%$ do desenvolvimento, 30 dias); 0,70 (dos 10 até 75\% do desenvolvimento, 40 dias); 1,05 (da floração até o início da maturação, 60 dias), e 0,85 (da maturação até a última colheita, 20 dias), de acordo com Doorenbos \& Kassam (1994).

Para a correção da fertilidade do solo foram utilizados fosfato monoamônico purificado (MAP) (11\% de N e 60\% de $\left.\mathrm{P}_{2} \mathrm{O}_{5}\right)$, nitrato de cálcio $(15,5 \%$ de $\mathrm{N}$ e $20 \%$ de $\mathrm{Ca})$, sulfato de magnésio $(9,5 \%$ de $\mathrm{Mg}$ e $12 \%$ de $\mathrm{S}$ ) e cloreto de potássio $\left(60 \% \mathrm{~K}_{2} \mathrm{O}\right.$ e $\left.48 \% \mathrm{Cl}\right)$, fazendo-se o balanceamento necessário de nutrientes. As doses diárias de nitrogênio, fósforo, cálcio, magnésio e potássio foram aplicadas na fertirrigação, seguindo recomendações de Trani \& Carrijo (2004), ressalvando que as dosagens de potássio foram ajustadas aos tratamentos do experimento. As quantidades totais aplicadas de $\mathrm{N}, \mathrm{P}_{2} \mathrm{O}_{5}, \mathrm{CaO}, \mathrm{MgO}, \mathrm{K}_{2} \mathrm{O}\left(\mathrm{D}_{1}\right)$ e $\mathrm{K}_{2} \mathrm{O}\left(\mathrm{D}_{2}\right)$, foram, respectivamente, 302,$10 ; 76,55 ; 123,40 ; 91,40 ; 79,95$ e $120,10 \mathrm{~kg} \mathrm{ha}^{-1}$.

Além dos macronutrientes, foram realizadas duas aplicações, em intervalo de 15 dias, na dose de 2,50 $\mathrm{kg} \mathrm{ha}^{-1}$ de Quelatec AZ como fonte de micronutrientes, recomendada pelo fabricante para pimentão, aos 70 e aos 90 dias após o transplante. Durante o ciclo foram feitas adubações foliares à base de cálcio e boro, elementos importantes na fase de frutificação, usando como fonte o produto $\mathrm{CaB} 10$, na dose recomendada para o pimentão.

O material de solo utilizado no experimento apresentou as seguintes características físicas: densidade global e das partículas de 1,65 e $2,57 \mathrm{~g} \mathrm{~cm}^{-3}$, respectivamente; porosidade total de $35,77 \%$; a distribuição da granulometria é 91,07; 3,60 e 5,33\% para areia, argila e silte, respectivamente; a retenção de água em base de massa na capacidade de campo (0,1 atm) e no ponto de murcha permanente (15 atm) é de 6,39 e $2,01 \mathrm{~g}$ $\mathrm{g}^{-1}$, respectivamente; a água disponível 
de 4,3\%; e a condutividade hidráulica saturada de $13,17 \mathrm{~cm} \mathrm{~h}^{-1}$.

Durante o experimento foram realizadas cinco colheitas. Amostras de três frutos por lisímetro foram retiradas, determinando-se a massa fresca em balança de precisão 0,01 g; em seguida as sementes foram removidas, reduziu-se os pimentões em pedaços e foram acondicionados em recipientes abertos de alumínio e levados para uma estufa de aeração forçada a $65^{\circ} \mathrm{C}$, durante aproximadamente 120 horas, até atingir massa constante. Em seguida, procedeu-se a nova pesagem do material para obtenção da massa seca.

Aos 112 dias do início do experimento, as plantas de cada tratamento foram retiradas e separadas em folhas, caule e raiz, sendo posteriormente pesados com precisão de 0,01 g para obtenção da massa fresca. Em seguida, as partes das plantas foram acondicionadas em sacos de papel, identificados e levados à estufa de aeração forçada a $65^{\circ} \mathrm{C}$, durante aproximadamente 72 horas, até atingir massa constante. Após este período, o material foi pesado novamente, para obtenção da massa seca.

Após a desidratação dos tecidos vegetais, procedeu-se à trituração das amostras e em seguida as mesmas foram acondicionadas em recipientes hermeticamente fechados, obtendo-se a amostra preparada para as análises. A partir desta amostra, foi obtido o extrato nitro-perclórico para ser utilizado para as determinações analíticas do $\mathrm{P}, \mathrm{K}, \mathrm{Ca}$, $\mathrm{Mg}, \mathrm{S}$ e $\mathrm{Na}$, exceto $\mathrm{N}$ e $\mathrm{Cl}$.

Nos tecidos vegetais, os teores dos nutrientes foram determinados conforme segue: para o nitrogênio $(\mathrm{N})$, utilizou-se a digestão sulfúrica pelo método de Kjeldhal; o fósforo foi determinado por espectrofotometria com molibdo-vanadato; o enxofre (S) foi determinado pelo método turbidimétrico do sulfato de bário; o potássio e o sódio por fotometria de chama; o cloreto $\left(\mathrm{Cl}^{-}\right)$ foi determinado pelo método de Mohr em um extrato aquoso, e o cálcio e o magnésio por espectrofotometria de absorção atômica (EAA) (Bezerra Neto \& Barreto, 2011).

Para a análise de nutrientes no solo, procedeu-se duas coletas, ambas consistindo de uma amostra simples retirada na camada 0-20 cm em cada lisímetro: a primeira antes da instalação do experimento, e a segunda aos 112 dias do início do experimento. A concentração de fósforo (P) foi determinada por espectrofotometria; o potássio $(\mathrm{K})$ e sódio (Na) foram determinados por fotometria de chama (extração com solução de Mehlich 1); e o cálcio (Ca) e o magnésio (Mg) por EAA, segundo metodologias propostas por Embrapa (2009).

Os resultados foram analisados no sistema computacional de análise de variância (SISVAR, v. 5.3) (Ferreira, 2011) e interpretados por meio das significâncias das análises de variância (ANOVA) e regressão, considerando-se o nível de probabilidade de $5 \%$ pelo teste $\mathrm{F}$.

Para estabelecer um modelo que representasse o fenômeno em estudo, utilizou-se o teste " $t$ " de Student para testar os coeficientes de regressão, e os coeficientes de determinação $\left(\mathrm{R}^{2}\right)$.

A apresentação das equações de regressão e suas interpretações foram realizadas de acordo com recomendação de Alvarez \& Alvarez (2003). A lâmina ótima foi determinada a partir das análises de regressão, onde o modelo quadrático foi derivado obtendo-se o ponto de máxima concentração do elemento.

\section{RESULTADOS E DISCUSSÃO}

Não houve efeito significativo da interação lâmina de irrigação $(\mathrm{L}) \mathrm{x}$ dose de potássio (D) sobre as concentrações dos nutrientes analisados nas folhas de pimentão, exceto para a concentração de $\mathrm{Cl}$, na qual verificou-se efeito significativo com nível de significância de $1 \%$. Em relação aos efeitos isolados dos fatores $\mathrm{L}$ e $\mathrm{D}$, houve efeito significativo com níveis de significância variando de 1 a $5 \%$ de probabilidade, para as concentrações de $\mathrm{K}, \mathrm{Mg}, \mathrm{S}$ e $\mathrm{Cl}$ nas folhas de pimentão, sendo que, para o $\mathrm{S}$, o fator $\mathrm{L}$ não promoveu efeito significativo sobre sua concentração. Para os nutrientes N, $\mathrm{P}, \mathrm{Ca}$ e $\mathrm{Na}$, não foi constatado efeito significativo dos fatores estudados sobre suas concentrações no tecido foliar do pimentão.

Em relação às concentrações de nutrientes nos frutos de pimentão, houve efeito significativo em níveis de probabilidade variando de 1 a $5 \%$ da interação L x D e dos fatores isolados L e D apenas para as concentrações de $\mathrm{K}, \mathrm{Ca}$ e $\mathrm{Cl}$ nos frutos de pimentão, no entanto, $\mathrm{Ke} \mathrm{Cl}$ não foram afetados pelo fator $\mathrm{L}$ isoladamente, bem como $\mathrm{Ca}$ não foi afetado pelo fator $\mathrm{D}$. Os demais nutrientes não foram influenciados significativamente pelos fatores estudados nem por sua interação.

A caracterização química dos solos dos lisímetros antes da aplicação dos tratamentos indicou concentração de fósforo igual a $250,25 \mathrm{mg} \mathrm{dm}^{-3}$, e de potássio, sódio, cálcio e magnésio iguais a 0,$09 ; 0,13 ; 8,69$ e $0,72 \mathrm{cmol}_{\mathrm{c}} \mathrm{dm}^{-3}$, respectivamente; ao final do experimento, estas concentrações foram 183,94 mg $\mathrm{dm}^{-3}$ para o fósforo, e 0,$06 ; 0,13 ; 9,17 \mathrm{e}$ $1,44 \mathrm{cmol}_{\mathrm{c}} \mathrm{dm}^{-3}$ para o potássio, sódio, cálcio e magnésio, nesta ordem.

As concentrações médias de $\mathrm{N}$, $\mathrm{P}, \mathrm{K}, \mathrm{Ca}, \mathrm{Mg}, \mathrm{S}, \mathrm{Na}, \mathrm{Cl}$, foram, nesta ordem, nas folhas e nos frutos, 32,69; 3,$38 ; 13,32 ; 4,88 ; 11,06 ; 2,71 ; 0,16$; $11,95 \mathrm{~g} \mathrm{~kg}^{-1}$, e 25,$92 ; 3,75 ; 26,00 ; 3,45$; 1,$76 ; 1,99 ; 0,32 ; 21,87 \mathrm{~g} \mathrm{~kg}^{-1}$, respectivamente. Sendo assim, as ordens de concentração de nutrientes nas folhas e nos frutos do pimentão fertirrigado foram $\mathrm{N}>\mathrm{K}>\mathrm{Cl}>\mathrm{Mg}>\mathrm{Ca}>\mathrm{P}>\mathrm{S}>\mathrm{Na}$ e $\mathrm{K}>\mathrm{N}>\mathrm{Cl}>\mathrm{P}>\mathrm{Ca}>\mathrm{S}>\mathrm{Mg}>\mathrm{Na}$, respectivamente.

Apesar da coleta das folhas ter sido realizada no final do ciclo da cultura, os teores de N, P, Ca e Mg encontram-se na faixa adequada, conforme indicada por Cavalcanti(2008). Este autor menciona como adequada, para o pimentão, a faixa de valores para $\mathrm{N}(30,0$ a 45,0$)$, $\mathrm{P}(3,0$ a 7,0$), \mathrm{Ca}(4,0$ a 6,0$)$ e $\mathrm{Mg}(10,0$ a 17,0), em $\mathrm{g} \mathrm{kg}^{-1}$. O potássio, como é um elemento altamente móvel no floema (Malavolta, 2006) é possível que tenha sido transportado das folhas para os frutos, conforme se verifica que o seu teor foi cerca de duas vezes superior ao teor nas folhas.

A concentração de $\mathrm{K}$ no fruto foi superior à sua concentração na folha, concordando com as observações de Malavolta (2006), que menciona que o K é completamente solúvel em água, conferindo sua alta mobilidade na planta em direção aos órgãos mais novos ou para os frutos em desenvolvimento, o mesmo não ocorrendo com o $\mathrm{Ca}$ e o 


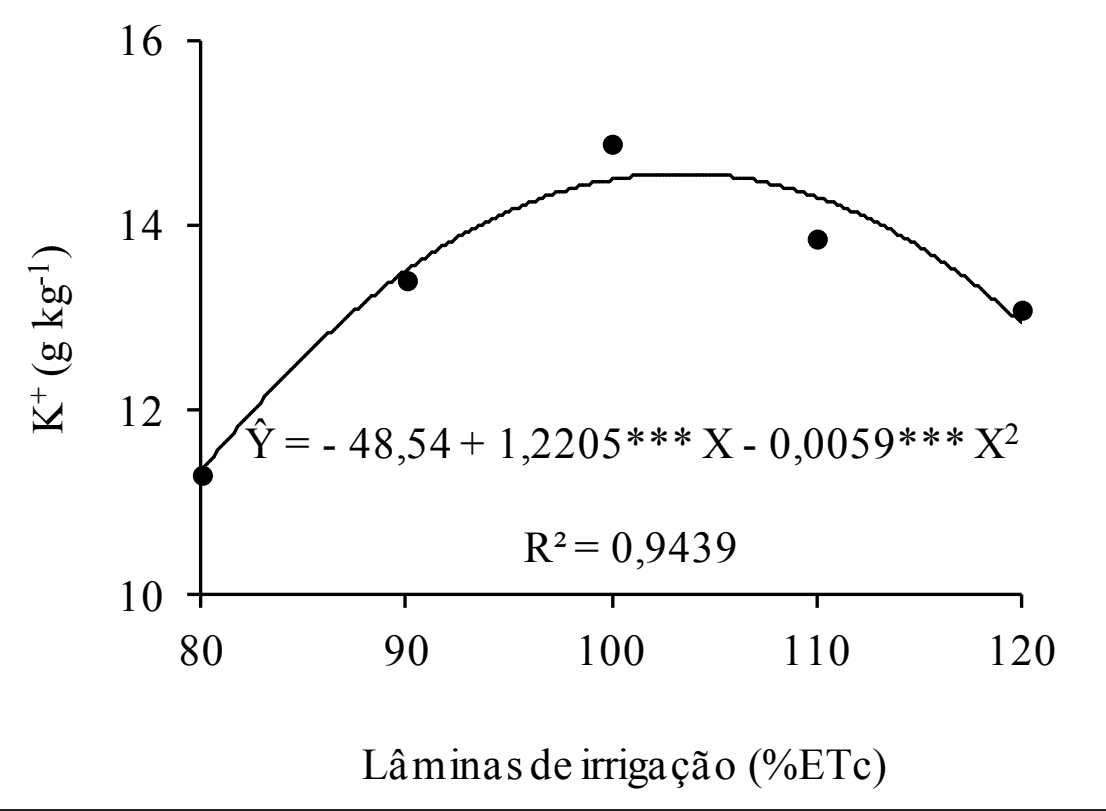

Figura 1. Concentração de potássio $\left(\mathrm{K}^{+}\right)$das folhas de pimentão fertirrigado, em função das lâminas de irrigação $(\% \mathrm{ETc})$; ***significativo a $0,1 \%$ de probabilidade pelo teste $\mathrm{t}$ (potassium concentration $\left(\mathrm{K}^{+}\right)$of the leaves of fertigated sweet pepper plants, depending on the irrigation depths (\%ETc); ***significant at $0.1 \%$ of probability by t test). Recife, UFRPE, 2010.

Mg, constatação também observada no presente experimento.

Da mesma forma, as concentrações de $\mathrm{Ca}, \mathrm{P}, \mathrm{S}$ e $\mathrm{Mg}$ nos tecidos de plantas de pimentão neste estudo foram inferiores aos encontrados por Marcussi (2005), quando determinaram as concentrações dos macronutrientes nos diferentes órgãos do híbrido de pimentão Elisa, sob fertirrigação em ambiente protegido, por meio de coletas de plantas durante o ciclo. Este autor verificou que as concentrações médias de cálcio, potássio, enxofre e magnésio no fruto foram 3,$3 ; 3,9 ; 5,1$ e 4,5 $\mathrm{g} \mathrm{kg}^{-1}$ de massa seca, respectivamente, durante o período de 60 a 140 dias após o transplantio.

Marcussi (2005) também verificou que na folha da planta de pimentão, dentre os macronutrientes, o potássio foi o que apareceu com maior concentração, em todo o ciclo estudado da cultura, com média de $50,5 \mathrm{~g} \mathrm{~kg}^{-1}$ de matéria seca, do transplantio até 140 dias após o transplante, seguido pelo nitrogênio, com média de $37,7 \mathrm{~g} \mathrm{~kg}^{-1}$, cálcio com $24,0 \mathrm{~g} \mathrm{~kg}^{-1}$, magnésio com 9,6 $\mathrm{g} \mathrm{kg}^{-1}$, enxofre com 4,8 $\mathrm{g} \mathrm{kg}^{-1}$ e o fósforo com $4,4 \mathrm{~g} \mathrm{~kg}^{-1}$.

A regressão apresentou uma resposta quadrática entre as concentrações de potássio nas folhas e as lâminas de irrigação (Figura 1). A derivada desta curva mostrou a lâmina de irrigação ótima de $103,43 \%$ da ETc sendo esta responsável pela máxima concentração de $\mathrm{K}$ nas folhas $\left(14,58 \mathrm{~g} \mathrm{~kg}^{-1}\right)$. Houve incrementos de 28,57 e $12,50 \%$ quando se comparou as concentrações de $\mathrm{K}$ nas folhas, decorrentes das lâminas de irrigação $\mathrm{L}_{1}$ $\left(11,34 \mathrm{~g} \mathrm{~kg}^{-1}\right)$ e $\mathrm{L}_{5}\left(12,96 \mathrm{~g} \mathrm{~kg}^{-1}\right)$ com o valor máximo. A concentração média de potássio $\left(\mathrm{K}^{+}\right)$nas folhas foi de 12,79 $\mathrm{g} \mathrm{kg}^{-1}$ para a dose $\mathrm{D}_{1}$ de potássio e de $13,85 \mathrm{~g} \mathrm{~kg}^{-1}$ para a dose $\mathrm{D}_{2}$.

A concentração de $\mathrm{Mg}$ nas folhas em função das lâminas de irrigação ajustou-se a modelo quadrático de regressão (Figura 2). As doses de K se apresentaram em níveis adequados, a ponto de não inibir a absorção dos nutrientes, exceto para os teores de $\mathrm{Mg}$ e S nas folhas. A lâmina de irrigação ótima de 105,54\% da ETc corresponde à máxima concentração de magnésio nas folhas $(12,67 \mathrm{~g}$ $\left.\mathrm{kg}^{-1}\right)$. Houve incrementos de $55,90 \%$ no teor de $\mathrm{Mg}$ nas folhas, entre a lâmina de $80 \%$ da ETc e $105,54 \%$ da ETc. A partir deste ponto até a lâmina de $120,0 \%$ da ETc houve uma diminuição no teor de $\mathrm{Mg}$ nas folhas e 12,99\% quando se comparou as concentrações observadas nas lâminas de irrigação $\mathrm{L}_{1}\left(8,12 \mathrm{~g} \mathrm{~kg}^{-1}\right)$ e $\mathrm{L}_{5}\left(11,21 \mathrm{~g} \mathrm{~kg}^{-1}\right)$ com o valor máximo.

A concentração média de $\mathrm{Mg}$ nas folhas foi de 12,09 $\mathrm{g} \mathrm{kg}^{-1}$ para a dose $\mathrm{D}_{1}$, e de $10,03 \mathrm{~g} \mathrm{~kg}^{-1}$ para a dose $\mathrm{D}_{2}$ de $\mathrm{K}$, corroborando a afirmação de Malavolta (2006), quando cita que alta concentração de $\mathrm{K}^{+}$no meio pode inibir competitivamente a absorção de $\mathrm{Mg}$, causando às vezes deficiência desse nutriente.

Com relação à concentração de $\mathrm{S}$ no tecido foliar, obteve-se 2,86 e 2,55 $\mathrm{g} \mathrm{kg}^{-1}$, para as doses $\mathrm{D}_{1}$ e $\mathrm{D}_{2}$ de $\mathrm{K}$, respectivamente. Observa-se que a concentração de $\mathrm{S}$ foi menor na maior dose de $\mathrm{K}$, talvez em função do maior teor de $\mathrm{Cl}^{-}$existente na maior dose, o qual pode inibir a absorção de S (Malavolta et al., 1997).

Quanto às concentrações de $\mathrm{Cl}^{-}$nas folhas e de $\mathrm{K}, \mathrm{Ca} \mathrm{e}^{-}$nos frutos de pimentão, estas apresentaram equações de regressão significativas ajustadas aos dados médios (Tabela 1).

Houve resposta a modelo linear de regressão crescente sobre o teor de $\mathrm{Cl}^{-}$ nas folhas de pimentão, em função das lâminas de irrigação estimado na dose $\mathrm{D}_{2}$ de potássio. Ocorreu um incremento de $96,12 \%$ ao se comparar os dados estimados pelo modelo matemático, entre as lâminas de irrigação $L_{1}\left(7,73 \mathrm{~g} \mathrm{~kg}^{-1}\right)$ $\mathrm{e}_{5}\left(15,16 \mathrm{~g} \mathrm{~kg}^{-1}\right)$.

Esses teores estão bem acima dos mencionados por Malavolta et al. (1997), ao citarem que as plantas, em geral, não necessitam mais do que $100 \mathrm{mg} \mathrm{kg}^{-1} \mathrm{de}^{-} \mathrm{Cl}^{-}$na matéria seca; no entanto, o tecido vegetal normalmente pode apresentar de 20 a 200 vezes mais, indicação de que o cloro não é tóxico quando encontrado em concentrações um pouco acima das necessidades da planta.

Da mesma forma, comparando com os teores de $\mathrm{Cl}^{-}$em folhas de pimentão encontrados por Silva et al. (2001), os do presente estudo também se encontram superiores. Esses autores, avaliando o efeito do $\mathrm{KCl}$ na concentração de $\mathrm{Cl}^{-}$em plantas de pimentão, encontraram as maiores concentrações de cloreto nas folhas de pimentão, sendo em média de $7.492 \mathrm{mg} \mathrm{kg}^{-1}$, considerados de acordo com os teores requeridos pelo pimentão, embora a produção de frutos tenha 


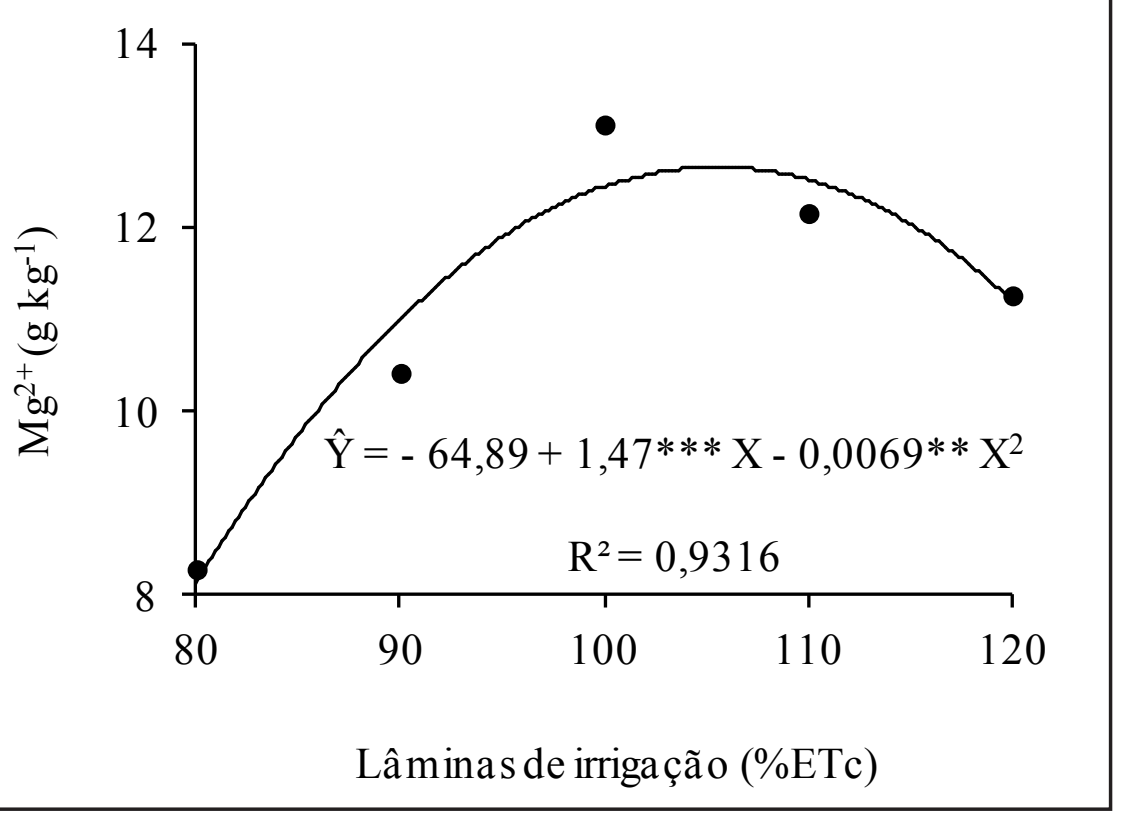

Figura 2. Concentração de magnésio $\left(\mathrm{Mg}^{2+}\right)$ das folhas de pimentão fertirrigado, em função das lâminas de irrigação (\%ETc); **e***significativos a $1 \%$ e $0,1 \%$ de probabilidade pelo teste $\mathrm{t}$, respectivamente (magnesium concentration $\left(\mathrm{Mg}^{2+}\right)$ of the leaves of fertigated sweet pepper plants, depending on the irrigation depths (\%ETc); *and*** significant at 1 and $0.1 \%$ of probability by t test, respectively). Recife, UFRPE, 2010.

diminuído (de 6,31 para $5,92 \mathrm{~kg} \mathrm{~m}^{-2}$ ).

Rubio et al. (2010a) também verificaram aumento da concentração de $\mathrm{Cl}^{-}$(em média $17 \mathrm{mg} \mathrm{g}^{-1}$ ) em folhas de pimentão (cultivar Somontano), em cultivo hidropônico, com adição de potássio $(0,2 ; 2,0 ; 7,0$ e $14,0 \mathrm{mM})$ na solução nutritiva contendo $\mathrm{NaCl}$. Esses autores também observaram que aumentando a concentração de $\mathrm{K}^{+}$na solução nutritiva, os teores foliares de $\mathrm{Ca}^{2+}$ e $\mathrm{Mg}^{2+}$ diminuíram, e aumentou os teores foliares de $\mathrm{K}^{+}$, diferentemente do comportamento observado neste experimento.

Com relação à concentração de $\mathrm{Ca}$ nas folhas, Rubio et al. (2009) observaram resultados contrários aos obtidos no presente experimento. Estes autores, ao estudarem um nível ótimo de $\mathrm{K}^{+}{\mathrm{e} \mathrm{Ca}^{2+}}^{2+}$ nas soluções nutritivas em plantas de pimentão, cultivar Somontano, cultivadas sob estresse salino moderado, e verificação da incidência de podridão apical nos frutos, constataram que a diminuição da concentração de $\mathrm{K}$ na solução nutritiva levou a um aumento significativo da concentração de Ca nas folhas (jovens e totalmente expandidas).

Houve um aumento linear na concentração de $\mathrm{K}$ nos frutos em função das lâminas de irrigação estimado no nível da dose de potássio $\mathrm{D}_{2}\left(120 \mathrm{~kg} \mathrm{ha}^{-1}\right)$. Foi constatado incremento de $27,99 \%$ quando se comparou os teores de $\mathrm{K}$ estimados pelo modelo com os obtidos na lâmina de irrigação $\mathrm{L}_{1}\left(24,01 \mathrm{~g} \mathrm{~kg}^{-1}\right) \mathrm{e}$ na lâmina de irrigação $L_{5}\left(30,72 \mathrm{~g} \mathrm{~kg}^{-1}\right)$.

O comportamento linear crescente da concentração de $\mathrm{Ca}$ no fruto para ambas as doses de $\mathrm{K}$ pode ser explicado pelas concentrações de $\mathrm{K}$ nessas doses estarem em níveis adequados, a ponto de não inibir a absorção de cálcio. Quando se fixou a dose de $\mathrm{K} \mathrm{em} 80 \mathrm{~kg} \mathrm{ha}^{-1}\left(\mathrm{D}_{1}\right)$, foi observado incremento de $40,44 \%$ nos teores de $\mathrm{Ca}$ nos frutos, entre as lâminas de irrigação $\mathrm{L}_{1}\left(2,91 \mathrm{~g} \mathrm{~kg}^{-1}\right)$ e $\mathrm{L}_{5}(4,09 \mathrm{~g}$ $\left.\mathrm{kg}^{-1}\right)$. Fixando-se a dose de $\mathrm{K}$ em $120 \mathrm{~kg}$ $\mathrm{ha}^{-1}\left(\mathrm{D}_{2}\right)$, houve incremento de $43,36 \%$ quando se comparou o teor de $\mathrm{Ca}$ nos frutos cultivados com a lâmina $\mathrm{L}_{1}(2,80$ $\mathrm{g} \mathrm{kg}^{-1}$ ) com os frutos cultivados com a lâmina $\mathrm{L}_{5}\left(4,01 \mathrm{~g} \mathrm{~kg}^{-1}\right)$.

Em cultivo hidropônico, Rubio et al. (2009) constataram uma redução no teor de $\mathrm{Ca}$ em frutos de pimentão cultivados com altas doses de $\mathrm{Ca}(8 \mathrm{mM}) \mathrm{e}$ $\mathrm{K}(14 \mathrm{mM})$, comparados às plantas não estressadas pela elevada salinidade da solução nutritiva.
A concentração de $\mathrm{Cl}^{-}$nos frutos de pimentão aumentou linearmente em função das lâminas de irrigação estimado no nível da dose de $\mathrm{K}$ de $120 \mathrm{~kg} \mathrm{ha}^{-1}\left(\mathrm{D}_{2}\right)$. Observou-se incremento de $23,82 \%$ ao se comparar os teores de $\mathrm{K}$ estimados pelo modelo com os observados na lâmina de irrigação $\mathrm{L}_{1}\left(19,35 \mathrm{~g} \mathrm{~kg}^{-1}\right) \mathrm{e}$ na lâmina de irrigação $\mathrm{L}_{5}\left(23,96 \mathrm{~g} \mathrm{~kg}^{-1}\right)$. Da mesma forma como ocorreu com os teores de $\mathrm{K}$ nas folhas, esta resposta para os teores de $\mathrm{K}$ nos frutos está associada ao fato de ser empregado o cloreto como íon acompanhante do $\mathrm{K}$ nos tratamentos do presente experimento.

Silva et al. (2001) também constataram que o $\mathrm{Cl}^{-}$foi acumulado em maior proporção nos frutos do que nas folhas do pimentão, e que também houve um aumento deste íon em resposta à adubação com $\mathrm{KCl}$.

As altas concentrações de $\mathrm{Cl}^{-}$encontradas tanto nas folhas quanto nos frutos de pimentão são justificados pelo elevado teor deste elemento no $\mathrm{KCl}$ utilizado como fonte de $\mathrm{K}$ na fertirrigação, equivalendo a $48 \%$ de $\mathrm{Cl}^{-}$, ainda que o solo dos lisímetros tenha uma textura predominantemente arenosa, e o $\mathrm{Cl}^{-}$sendo bastante móvel tanto no solo quanto na planta.

As concentrações foliares de $\mathrm{K}$ refletiram em máximas produtividades em função da dose de potássio $D_{1}(21,78 \mathrm{t}$ $\left.\mathrm{ha}^{-1}\right)$ e dose de potássio $\mathrm{D}_{2}\left(23,19 \mathrm{tha}^{-1}\right)$, cujas lâminas de irrigação ótimas estimadas foram 102,08 e 97,68\% da ETc, para as doses 1 e 2, respectivamente, segundo Albuquerque et al. (2011a), no mesmo estudo e avaliando o crescimento e o rendimento do pimentão sob regimes de fertirrigação. Estes mesmos autores encontraram o máximo número de frutos por planta sendo 7,84 e 7,66, e peso médio dos frutos sendo $85,50 \mathrm{e}$ $79,34 \mathrm{~g}$ rruto $^{-1}$, respectivamente para as doses de potássio $\mathrm{D}_{1}$ e $\mathrm{D}_{2}$.

De maneira semelhante, Rubio et al. (2010b), estudando os efeitos de diferentes doses de $\mathrm{Ca}^{2+} \mathrm{e} \mathrm{K}^{+}$sobre a produção de frutos e parâmetros de qualidade de plantas de pimentão, cultivar Orlando, em cultivo hidropônico, verificaram que alto nível de $\mathrm{K}\left(14 \mathrm{mmol} \mathrm{L}^{-1}\right)$, reduziu a produção de frutos comercializáveis em $25 \%$, como resultado de uma diminuição tanto no número de frutos por planta 
Tabela 1. Equações de regressão ajustadas aos dados médios das concentrações de cloreto $\left(\mathrm{Cl}^{-}\right)$nas folhas, e de potássio $\left(\mathrm{K}^{+}\right)$, cálcio $\left(\mathrm{Ca}^{2+}\right)$ e cloreto $\left(\mathrm{Cl}^{-}\right)$nos frutos de pimentão em função das lâminas de irrigação estimadas nos níveis das doses de potássio $\left(\mathrm{D}_{1}\right.$ e $\left.\mathrm{D}_{2}\right)$, com os respectivos coeficientes de determinação $\left(\mathrm{R}^{2}\right)$ (regression equations adjusted to mean data of chloride contents $\left(\mathrm{Cl}^{-}\right)$in the leaves, and potassium $\left(\mathrm{K}^{+}\right)$, calcium $\left(\mathrm{Ca}^{2+}\right)$ and chloride contents $\left(\mathrm{Cl}^{-}\right)$in sweet pepper fruits depending on the irrigation depths estimated in potassium levels $\left(\mathrm{D}_{1}\right.$ and $\left.\mathrm{D}_{2}\right)$, with their respective determination coefficients $\left(\mathrm{R}^{2}\right)$ ). Recife, UFRPE, 2010.

\begin{tabular}{|c|c|c|c|}
\hline \multicolumn{2}{|c|}{ Órgão/Variáveis } & Equações de regressão ajustadas & $\mathbf{R}^{2}$ \\
\hline \multicolumn{4}{|c|}{ Folhas } \\
\hline $\mathrm{Cl}^{-}$ & $\left(\mathrm{D}_{2}\right)$ & $\hat{Y}=-7,13+0,19 * * * X$ & 0,6816 \\
\hline \multicolumn{4}{|c|}{ Frutos } \\
\hline $\mathrm{K}^{+}$ & $\left(D_{2}\right)$ & $\hat{Y}=10,57+0,168^{* *} X$ & 0,6890 \\
\hline \multirow[t]{2}{*}{$\mathrm{Ca}^{2+}$} & $\left(D_{1}\right)$ & $\hat{\mathrm{Y}}=0,56+0,0294^{* *} \mathrm{X}$ & 0,8753 \\
\hline & $\left(\mathrm{D}_{2}\right)$ & $\hat{\mathrm{Y}}=0,37+0,0303^{* *} \mathrm{X}$ & 0,5137 \\
\hline $\mathrm{Cl}^{-}$ & $\left(\mathrm{D}_{2}\right)$ & $\hat{\mathrm{Y}}=10,13+0,1152 * * \mathrm{X}$ & 0,6743 \\
\hline
\end{tabular}

**e***Significativos a $1 \%$ e $0,1 \%$ de probabilidade pelo teste $t$, respectivamente.

quanto no peso médio de frutos.

Entretanto, Marcussi et al. (2004a), avaliando a produção de frutos de pimentão, cultivar Elisa, obtidos em plantas fertirrigadas com doses de $\mathrm{N}$ e $\mathrm{K}$ estimadas pela quantidade destes nutrientes acumulada na planta, constataram que o maior número de frutos não foi alcançado com a maior dose $(150 \%$ de $\mathrm{Ne} \mathrm{K}$ ), enquanto que a produtividade de frutos comerciais e peso médio de frutos foram obtidos com a maior dose aplicada.

A partir da máxima produtividade do pimentão $\left(23,19 \mathrm{t} \mathrm{ha}^{-1}\right)$ obtida aplicando a maior dose de $\mathrm{K}\left(120 \mathrm{~kg} \mathrm{ha}^{-1}\right.$ $\mathrm{K}_{2} \mathrm{O}$ ), as exportações de nutrientes, em $\mathrm{kg} \mathrm{ha}^{-1}$, estimadas na massa seca dos frutos, em média, foram $\mathrm{N}(23,05)$, $\mathrm{P}(3,52), \mathrm{K}(26,57), \mathrm{Ca}(3,47), \mathrm{Mg}$ $(1,70), \mathrm{S}(1,62), \mathrm{Na}(0,31)$ e $\mathrm{Cl}(20,73)$. A ordem de exportação de nutrientes pelos frutos do pimentão fertirrigado foi $\mathrm{K}>\mathrm{N}>\mathrm{Cl}>\mathrm{P}>\mathrm{Ca}>\mathrm{Mg}>\mathrm{S}>\mathrm{Na}$. Com base nestes valores de exportação de nutrientes, e na analise da fertilidade do solo é possível se estimar uma adubação ou fertirrigação que atenda às necessidades da cultura para obtenção de uma boa produtividade.

No entanto, a cultivar de pimentão Elisa, conseguiu acumular mais $\mathrm{P}$ nos frutos do que os demais nutrientes, seguido de N, S, e K com percentuais semelhantes, enquanto que $\mathrm{Ca} \mathrm{e} \mathrm{Mg}$ foram os macronutrientes menos acumulados nos frutos (Marcussi et al. 2004b). Em condição de campo, Filgueira (2003) menciona que a exportação dos macronutrientes por frutos de pimentão, em $\mathrm{kg} \mathrm{ha}^{-1}$, foi 24,2 para $\mathrm{K}, 17,7$ para $\mathrm{N}$, 3,7 para $\mathrm{Ca}, 2,3$ para $\mathrm{P}, 1,4$ para $\mathrm{Mg}$ e 1,4 para S. Percebe-se que, exceto o nutriente $\mathrm{Ca}$, os valores de exportação dos demais nutrientes, do presente trabalho, foram superiores.

Analisando conjuntamente toda a parte aérea das plantas de pimentão, Fontes et al. (2005) mencionam que a quantidade de nutrientes acumulados em $\mathrm{kg} \mathrm{ha}^{-1}$ foi 100,00 para K; 78, 17 para N; 27,36 para $\mathrm{Ca} ; 13,98$ para $\mathrm{P} ; 8,05$ para $\mathrm{S}$ e 7,56 para $\mathrm{Mg}$. Ressalta-se que além da adubação, a quantidade de nutrientes extraída do solo ou exportada pelas culturas varia de forma bastante ampla, influenciada por uma série de fatores, dentre os quais: cultivar empregado, condições do solo, variações climáticas, disponibilidade de água, produtividade obtida e ciclo da cultura (Filgueira, 2003). Corroborando esta afirmação, Fernandes et al. (1971), em estudo para avaliar a extração de nutrientes pelas variedades de pimentão Avelar e Ikeda, cultivadas em condições de campo, verificaram que não ocorreu diferença significativa no início e no total dos nutrientes absorvidos no final; porém, aos 75 dias de idade, uma planta da variedade Avelar absorveu mais que uma da Ikeda: $14,7 \%$ N, $15,4 \%$ P, $18,4 \%$ K, $16,9 \% \mathrm{Ca}, 18,1 \% \mathrm{Mg}$ e $21,8 \% \mathrm{~S}$.

Albuquerque et al. (2011b) verificaram um aumento na condutividade elétrica da solução drenada dos solos dos lisímetros deste estudo com a aplicação da maior lâmina de irrigação (120\% da $\mathrm{ETc})$, possivelmente pelo incremento de $\mathrm{Cl}^{-}$proveniente da fertirrigação, o qual é um micronutriente absorvido em quantidades menores do que os macronutrientes essenciais (Marschner, 1995).

Diante do exposto, é possível inferir que, de maneira geral, perante a escassez de informações sobre lâminas de irrigação e doses de potássio para uma região de grande produção de hortaliças (caracterizada como cinturão-verde), aplicando-se uma lâmina de irrigação próxima de $100 \%$ da evapotranspiração da cultura e dose de $\mathrm{K}$ de $80 \mathrm{~kg} \mathrm{ha}^{-1}$ de $\mathrm{K}_{2} \mathrm{O}$, obtêm-se níveis adequados dos macronutrientes nas plantas de pimentão. Dessa forma, evita-se condições de deficiência nutricional, o que pode contribuir para um bom rendimento da cultura, além de minimizar a perda de nutrientes devido a aplicações excessivas de água e fertilizantes.

\section{AGRADECIMENTOS}

Os autores expressam seus agradecimentos ao Programa de Pós-Graduação em Engenharia Agrícola da UFRPE (PPGEA/UFRPE), à Coordenação de Aperfeiçoamento de Pessoal de Nível Superior (CAPES), ao Conselho Nacional de Desenvolvimento Científico e Tecnológico (CNPq) e ao Instituto Nacional de Ciência e Tecnologia em Salinidade/CNPq pela concessão de bolsas e apoio financeiro. Pesquisa financiada pelo CNPq, Projeto Universal/ Processo 4843302007-1.

\section{REFERÊNCIAS}

ALBUQUERQUE FS; SILVA EFF; ALBUQUERQUE FILHO JAC; NUNES MFFN. 2011a. Crescimento e rendimento de pimentão fertigado sob diferentes lâminas de irrigação e doses de potássio. Revista Brasileira de Engenharia Agrícola e Ambiental 15: 686-694.

ALBUQUERQUE FS; SILVA EFF; SOUZAAER; ROLIM MM. 2011b. Lixiviação de potássio em um cultivo de pimentão sob lâminas de irrigação e doses de potássio. Revista Caatinga 24: $135-144$.

ALBUQUERQUE FILHO JAC; LIMA VLA; MENEZES D; AZEVEDO CAV; DANTAS NETO J; SILVA JÚNIOR JG. 2009. Características vegetativas do coentro 
submetido a doses do polímero hidroabsorvente e lâminas de irrigação. Revista Brasileira de Engenharia Agrícola e Ambiental 13: 671-679.

ALVAREZ VVH; ALVAREZ GAM. 2003. Apresentação de equações de regressão e suas interpretações. Boletim Informativo da Sociedade Brasileira de Ciência do Solo 28: 28-32.

BERNARDO S; SOARES AA; MANTOVANI EC. 2008. Manual de irrigação. 8. ed. Viçosa, MG: UVF. 625p.

BEZERRA NETO E; BARRETO LP. 2011. Análises químicas e bioquímicas em plantas. Recife: UFRPE, Editora Universitária. 267p.

CAVALCANTI FSA. 2008. Recomendações de adubação para o Estado de Pernambuco. $2^{\mathrm{a}}$ aproximação. Recife: Instituto Agronômico de Pernambuco. 212p.

DOORENBOS J; KASSAM AH. 1994. Efeito da água no rendimento das culturas. Campina Grande, PB: UFPB. 306p.

ECHER MM; FERNANDES MCA; RIBEIRO RLD; PERACCHI AL. 2002. Avaliação de genótipos de Capsicum para resistência ao ácaro branco. Horticultura Brasileira 20: 217-221.

EMBRAPA. Centro Nacional e Pesquisa em Solos. 2006. Sistema brasileiro de classificação de solos. 2. ed. Rio de Janeiro: Embrapa Solos. $306 \mathrm{p}$.

EMBRAPA. 2009. Manual de análises químicas de solos, plantas e fertilizantes. Embrapa Informação Tecnológica. 2. ed. Brasília. 627p.

FERNANDES PD; OLIVEIRA GD; HAAG HP.
1971. Nutrição mineral de hortaliças XV. Estudos da nutrição mineral de duas variedades de pimentão cultivado em condições de campo. Anais da E.S.A. "Luiz de Queiroz" 28: 145-151.

FERREIRADF. 2011. Sisvar: a computer statistical analysis system. Ciência e Agrotecnologia 35: 1039-1042.

FILGUEIRA FAR. 2003. Solanáceas: agrotecnologia moderna na produção de tomate, batata, pimentão, pimenta, berinjela e jiló. Lavras: UFLA. 333p.

FONTES PCR; DIAS EN; GRAÇA RN. 2005. Acúmulo de nutrientes e método para estimar doses de nitrogênio e de potássio na fertirrigação do pimentão. Horticultura Brasileira 23: 275-280.

MALAVOLTA E; VITTI GC; OLIVEIRA SA. 1997. Avaliação do estado nutricional das plantas: principios e aplicações. 2. ed. Piracicaba: POTAFÓS. 319p.

MALAVOLTA E. 2006. Manual de nutrição mineral de plantas. São Paulo: Ed. Ceres. $630 \mathrm{p}$.

MARCUSSI FFN; GODOY LJG; VILLAS BÔAS RL. 2004a. Fertirrigação nitrogenada e potássica na cultura do pimentão baseada no acúmulo de N e K pela planta. Irriga 9: 41-51.

MARCUSSI FFN; VILLAS BÔAS RL; GODOY LJG; GOTO R. 2004b. Macronutrient accumulation and partioning in fertigated sweet pepper plants. Scientia Agricola 61: 62-68.

MARCUSSI FFN. 2005. Uso da fertirrigação e teores de macronutrientes em planta de pimentão. Engenharia Agrícola 25: 642-650.
MARSCHNER H. 1995. Mineral nutrition of higher plants. Londres: Academia Press. 889p.

OLIVEIRA MVAM; VILLAS BÔAS RL. 2008. Uniformidade de distribuição do potássio e do nitrogênio em sistema de irrigação por gotejamento. Engenharia Agrícola 28: 95-103.

PIZARRO F. 1996. Riegos localizados de alta frecuencia (RLAF): goteo, microaspersión, exudácion. 3. ed. Madrid: Mundi-Prensa. 511p.

RUBIO JS; GARCÍA-SÁNCHEZ F; RUBIO F; MARTÍNEZ V. 2009. Yield, blossom-end rot incidence, and fruit quality in pepper plants under moderate salinity are affected by $\mathrm{K}^{+}$ and $\mathrm{Ca}^{2+}$ fertilization. Scientia Horticulturae 119: 79-87.

RUBIO JS; GARCÍA-SÁNCHEZ F; RUBIO F; GARCÍA AL; MARTÍNEZ V. 2010a. The importance of $\mathrm{K}^{+}$in ameliorating the negative effects of salt stress on the growth of pepper plants. European Journal of Horticultural Science 75: 33-41.

RUBIO JS; GARCÍA-SÁNCHEZ F; FLORES P; NAVARRO JM; MARTÍNEZ V. 2010b. Yield and fruit quality of sweet pepper in response to fertilization with $\mathrm{Ca}^{2+}$ and $\mathrm{K}^{+}$. Spanish Journal of Agricultural Research 8: 170-177.

SILVA MAG; BOARETTO AE; FERNANDES HG; SCIVITTARO WB. 2001. Efeito do cloreto de potássio na salinidade de um solo cultivado com pimentão, Capsicum annuum L., em ambiente protegido. Acta Scientiarum 23: 1085-1089.

TRANI PE; CARRIJO OA. 2004. Fertirrigação em hortaliças. Campinas: Instituto Agronômico. 53p. (Boletim Técnico IAC, 196). 